Running Head: Motherhood as the vehicle for change

\begin{abstract}
Preterm birth represents an interruption to the normal development of maternal identity and is considered a highly stressful event for adult mothers. However, no research has investigated whether or how preterm birth impacts on the adolescent mother's transition to motherhood. The current study aimed to explicate the experience of being a mother for adolescent women who experienced a preterm or term birth in Australia. This Interpretative Phenomenological Analysis study analysed interviews with 14 primaparous, English speaking adolescent mothers (15-19yrs; 10 Preterm \& 4 Full-term) who participated in three interviews over a 12month period. Findings suggested few differences in the experience of being a mother due to infant birth status. Instead, the experience of being a mother was fundamentally about transformations to the self. The young women constructed themselves differently as a result of being mothers. Changes included moving away from delinquent behaviours, development of internal resources, growth of a positive view of self, gaining meaning in their lives, and reconciling idealised and actual notions of self and other. This research adds to our understanding of how motherhood shapes the adolescent women's lives, while also challenging our assumptions about the impact of preterm and full-term birth for adolescent mothers.
\end{abstract}


Motherhood as a vehicle for change

Motherhood as the vehicle for change in Australian adolescent women of preterm and full term infants.

The transition to motherhood can be one of life's more challenging and complex transitions (Cowan \& Cowan, 2000). Having an infant fundamentally changes the woman and the way that she interacts with the world (Mercer, 1995; Smith, 1999). Adult women have reported that motherhood leads to a positive change in priorities, life direction, and self-perception (Smith, 1999). Much research has been concerned with how adolescent women simultaneously manage these demands with the concurrent developmental demands of adolescence.

Adolescence, usually defined as the second decade of life, is a time of prolific change. During the adolescent period both girls and boys undergo major changes in cognitive functioning, physical functioning, affective regulation, social functioning, moral reasoning, and identity (Meeus, 2011; Zimmer-Gembeck, Ducat, \& Collins, 2011). Cognitively, formal operational thought develops between the ages of 10 and 18, and this involves the ability to envisage and reason about alternatives, and plan for the future (Piaget, 2001). These new skills mean adolescents become more facile at predicting the consequences of their actions and adopting the perspective of another (Gilligan \& Belenky, 1980). However, these skills may not yet be easily accessible and this, along with their level of egocentrism and role experimentation, may influence their ability to parent successfully (Mercer, 1980; Sadler, 1983).

The new cognitive skills also enable adolescents to notice inconsistencies in their own lives (McAdams, 1993). McAdams posits that noticing that behaviour differs in context or around different people leads to a realisation that one is not consistently being one's 'real self'. The disparity leads to questioning 'who is the real me?' Who am I?, a question that is answered by exploring past experiences to develop a sense of self that is continuous through 
time. The development of identity has been proposed as a key task of adolescence (Erikson, 1968), when people develop a narrative identity that conveys to self and others who they are now, how they came to be, and where their lives may go in the future (McAdams, 1993; McLean \& Pasupathi, 2012). Becoming a mother is a transition that needs to be incorporated into the young woman’s identity and sense of self (Mercer, 1980, 2004).

In Australia under half of adolescent pregnancies are parented and the other half are terminated, with relinquishment of the infant for adoption almost non-existent (Condon \& Corkindale, 2002; Williams \& Davidson, 2004). Australian figures from 2011 suggest 3.7\% of births were to women under the age of 20 (Li, Zeki, Hilder, \& Sullivan, 2013), which is low compared to countries such as the United States of America, Canada, and the United Kingdom (Bearinger, Sieving, Ferguson, \& Sharma, 2007).

Worldwide, becoming a parent as an adolescent is considered problematic and in need of urgent policy and program action (Kumar, Kumar Singh, Kumar, \& Parasuraman, 2013). Some concerns are the adolescent woman's capacity to parent sensitively (Riva Crugnola, Ierardi, Gazzotti, \& Albizzati, 2014), poor maternal mental health (Kleiber \& Dimidjian, 2014), and perpetuation of high levels of disadvantage (Bradbury, 2006). While there is growing acknowledgement that background social factors contribute to both early childbearing and unfavourable maternal and child outcomes (Lee \& Gramatnev, 2006; SmithBattle, 2012), policies in developed countries that are designed to make parenting less attractive also contribute to the marginalisation of adolescent mothers, and exacerbate the stigma experienced by adolescent mothers (SmithBattle, 2013; Yardley, 2008).

Less well researched is the proposition that parenting may be a positive experience for adolescent women. Barratt, Roach, Morgan, and Colbert (1996) found that adolescent mothers reported higher well-being post-partum than same aged peers, while Hunt-Morse (2002) found that motherhood assisted with the development of identity and role formation. 
Motherhood as a vehicle for change

Fletcher (2012) found that adolescent childbearing may be protective for drug use and binge drinking. Similarly, motherhood often serves as a catalyst for lifestyle changes (Breen, 2014; Sheeran, Jones, \& Rowe, in press).

Despite this, Hanna (2001) reported how Australian adolescent mothers faced negative attitudes. Adolescent mothers are acutely aware of widely held stereotypes depicting them as 'not good enough mothers' and feel they need to disassociate themselves from a teenage mother identity (Romagnoli \& Wall, 2012). Typically, adolescent mothers are seen as a homogeneous group of immature, irresponsible, single, benefit-dependent, unfit parents (Campion, 1995), who deviate from ideals of motherhood (Arendell, 2000). The lack of acknowledgement of the heterogeneity of adolescent mothers’ knowledge, attitudes, skills, and abilities has significant ramifications for targeted service provision and service utilisation by adolescent mothers (Hanna, 2001).

One area neglected in the literature is how adolescent mothers' experiences of being a mother differ depending on their infant's birth status. Research with adult mothers suggests preterm birth is associated with a range of acute and chronic stressors both in hospital, and during the transition home (Davis, Edwards, \& Mohay, 2003). The experience of having a preterm infant is highly stressful (Carter, Mulder, Bartram, \& Darlow, 2005), is contrary to birth expectations, and mothers feel unprepared (Whitfield, 2003). Disorders such as depression (Miles, Holditch-Davis, Schwartz, \& Scher, 2007), PTSD (Shaw, Bernard, Storfer-Isser, Rhine, \& Horwitz, 2013), and anxiety (Carter et al., 2005) are more common following preterm birth (Meyer et al., 1995) and can interrupt the development of maternal identity (Mercer, 1995; Reid, 2000).

The limited literature examining adolescents’ experiences of preterm birth suggests that infant hospitalization exacerbates challenges experienced by all adolescent mothers (e.g., transportation difficulties) and exposes adolescent mothers to perceived negative judgment by 
Motherhood as a vehicle for change

hospital staff, but does not detract from the joy of being a mother (Sheeran, Jones, \& Rowe, 2013; Sheeran et al., in press). Further, Farnell, Jones, Rowe, and Sheeran (2012) found adolescent mothers experience less distress following preterm birth than adult mothers. What remains unclear is whether infant birth status changes how adolescent mothers navigate motherhood.

\section{Research Aims}

Arguably, it is important to understand the meaning ascribed by young women to the experience of being an adolescent mother. Yet, few studies have focussed on young women's experiences of being a mother. Little is known about what it means to be an adolescent mother, or whether having a preterm infant changes what it means to be a mother. The current study addressed this gap by exploring the lived experience of being a mother of a preterm or full-term infant.

\section{Method}

\section{Participants}

Data for the current project were gathered as part of a larger research project examining use of community support services and support needs of adolescent mothers of preterm and full term infants. A total sampling strategy was utilised for the larger project, recruiting young mothers from 4 hospitals in South East Queensland, Australia. The 14 young women in the current study were the only women from the larger sample $(\mathrm{N}=40)$ to provide interviews at all 3 data collection points. Participants were aged 15-19 years old, English speaking, primiparous, and had recently given birth to either a preterm $(<37$ weeks completed gestation, $\mathrm{N}=10$ ) infant who was in the special care nursery (SCN) or a full term infant $(\geq 37$ weeks, $N=4)$. Table 1 describes the characteristics of each mother. Pseudonyms have been used throughout to protect the mothers’ identities. 
Running Head: Motherhood as the vehicle for change

Table 1. Characteristics of participants

\begin{tabular}{|c|c|c|c|c|c|c|c|}
\hline Name & Age & Birth status & Living arrangement & $\begin{array}{l}\text { Length of time in } \\
\text { hospital }\end{array}$ & $\begin{array}{l}\text { Length of } \\
\text { relationship }\end{array}$ & Education & Risk factors \\
\hline Laura & 18 & PT 26 wks & Paternal parents & $\begin{array}{l}12 \text { wks } \\
\text { NICU/SCN }\end{array}$ & $<12$ months & Grade 10 & $\begin{array}{l}\text { Previous homelessness, hx of drug/alcohol use, own } \\
\text { mother MHI, conception following one night stand }\end{array}$ \\
\hline Emily & 15 & PT 28 wks & $\begin{array}{l}\text { At risk of } \\
\text { homelessness }\end{array}$ & $\begin{array}{l}11 \text { wks } \\
\text { NICU/SCN }\end{array}$ & N/A & Grade 9 & $\begin{array}{l}\text { Own mother IV drug user, FOB MHI, DV by FOB, } \\
\text { poor social support }\end{array}$ \\
\hline Jade & 17 & PT 30 wks & Maternal parents & 4 wks SCN & 12 months & Grade 12 & $\begin{array}{l}\text { Discovery of pregnancy at } 25 \text { wks, completed school } \\
\text { while pregnant, good family support }\end{array}$ \\
\hline Holly & 17 & PT 31 wks & Renting with FOB & 6 wks NICU/SCN & 9 months & Grade 10 & $\begin{array}{l}\text { Own mother IV drug user, removed from mothers } \\
\text { care/foster care by CS, FOB jailed, sisters children } \\
\text { removed by CS, FOB parents alcohol use }\end{array}$ \\
\hline Lisa & 15 & PT 31 wks & $\begin{array}{l}\text { Respective parents' } \\
\text { houses }\end{array}$ & 4 wks SCN & $>12$ months & Grade 9 & $\begin{array}{l}\text { Good family support, good relationship with FOB, both } \\
\text { self and FOB engaged in school }\end{array}$ \\
\hline Juliana & 17 & PT 33 wks & $\begin{array}{l}\text { Mortgage on FOB's } \\
\text { house }\end{array}$ & 2 wks SCN & 12 months & Tafe/Trade & Good family support, FOB securely employed \\
\hline Skye & 19 & PT 34 wks & Renting with FOB & 3 wks SCN & 4 years & Grade 10 & $\begin{array}{l}\text { Large extended family, long term relationship with } \\
\text { FOB, planned pregnancy }\end{array}$ \\
\hline Lily & 19 & PT 35 wks & Paternal parents & 3 wks SCN & 2 years & Grade 12 & Good family support, FOB securely employed \\
\hline Bronte & 18 & PT 35 wks & Renting with fiancé & 3 wks SCN & 4 years & Grade 10 & $\begin{array}{l}\text { Good family support, FOB securely employed, } \\
\text { pregnancy planned }\end{array}$ \\
\hline Renee & 17 & PT 35 wks & $\begin{array}{l}\text { Renting with partner } \\
\text { not FOB }\end{array}$ & 6 wks SCN & 7 months & Grade 9 & $\begin{array}{l}\text { Pregnancy following one night stand, some family } \\
\text { support, DV by current partner }\end{array}$ \\
\hline Jenna & 18 & FT & Renting with FOB & 3 days & 10 months & Grade 10 & $\begin{array}{l}\text { Good family support, pregnancy following one night } \\
\text { stand, FOB securely employed }\end{array}$ \\
\hline Claire & 18 & FT & $\begin{array}{l}\text { Mortgage on fiancé's } \\
\text { house }\end{array}$ & 3 days & 3 years & $\begin{array}{l}\text { Some } \\
\text { University }\end{array}$ & $\begin{array}{l}\text { Good family support, planned pregnancy, FOB } \\
\text { securely employed }\end{array}$ \\
\hline Danielle & 17 & FT & Renting own house & 2 days & Recently ended & Grade 9 & $\begin{array}{l}\text { Good family support, FOB securely employed and } \\
\text { supportive }\end{array}$ \\
\hline Tenielle & 18 & FT & Boarding house & 3 days & N/A & Grade 10 & $\begin{array}{l}\text { Poor family support, hx of family violence, pregnancy } \\
\text { following one night stand, hx of drug and alcohol use }\end{array}$ \\
\hline
\end{tabular}


Running Head: Motherhood as the vehicle for change

\section{Design and procedure}

The current research employed a qualitative longitudinal design, to investigate the lived experience of being a mother over a 12-month period. Interpretative Phenomenological Analysis (IPA) (Smith, Flowers, \& Larkin, 2009) is an inductive, data-driven, theme-building approach that later integrates findings within existing theoretical models (Smith, 2011). Each participant was individually interviewed at three time points: 1 week prior to the infant being discharged from the SCN (PT) or within 2 days post birth to 1-week post discharge (FT); 3-4 months post discharge; and 12 months post discharge.

Approval for the study was granted by the relevant institutional and hospital research ethics committees. Consistent with Australian ethical guidelines (2007) that consider maturity level rather than age for independent consent, participants provided informed consent to participate without the need for parental consent. The guidelines also suggest seeking parental consent is unethical where there is estrangement or abuse and where women who give birth are now able to consent to procedures for their infants. Three guided interviews were conducted in the participants' homes by the first author. All questions were non-directive, asked in plain, neutral language, with the interviewer following the participant's lead and prompting as needed. Interviews explored the following areas:

- Background demographic details

- Infant development

- Experiences of parenting (e.g., Could you tell me a little about your own experience since coming home from hospital?)

- Coping/support

- Impact on life (e.g., "Can you tell me a little about how you think having _ has impacted on your life").

- Expectations of parenting (e.g., Is parenting what you expected it would be - can you tell me about this)

- Perceived impact of prematurity (e.g., How do you think having a preterm infant has influenced your experience of being a mother?)

Interviews were digitally recorded and were 45 minutes to 1.5 hours in length. All interviews were transcribed verbatim. Participants also completed a questionnaire booklet 
Motherhood as a vehicle for change

and social support network activity as part of data collection for the larger study (see Farnell et al, 2012).

\section{Data analysis}

Data were analysed using the steps outlined in the IPA process (Smith, 2011; Smith \& Osborn, 2008). The aim was to report core themes, supported by excerpts, and accompanied by descriptive and interpretative commentary. To maintain an idiographic focus (Smith et al., 2009), each interview was analysed separately with descriptive comments and emergent themes noted. Interconnections, convergence, and divergence in themes across participants were then noted and core themes were written as a descriptive narrative backed up by example quotes. Time 1 interviews were analysed and aggregated, followed by time 2, and then time 3. Core themes across time were then identified and final themes were developed, synthesizing the material across time and participant.

Copies of emergent themes were provided to the research team to assess coherence. Cross checking was undertaken to explore how earlier analyses across time and within participants were represented by the central organizing themes, ensuring that a Gestalt had been reached. Analysis continued into the write up of the results and discussions sections, as integration and interpretation exposed new aspects of the data, and identified aspects of the experience that were not adequately represented. Detailed information about the coding and interpretative processes (including reflexivity and rigour) are outlined in Sheeran (2012).

\section{Reflexive note}

Smith et al argue researchers are unable to completely remove themselves from the research process and are intimately involved in the meaning-making process (Smith, Osborn, \& Jarman, 1999). Consistent with the hermeneutic tradition in Interpretative Phenomenological Analysis (IPA) (Smith et al., 2009), it is important to consider what I, as first author and principal investigator, brought to the research project. I was born full term to 
Motherhood as a vehicle for change

an adolescent mother and my mother's accounts of her early parenting years left me feeling it was a challenging experience for her. I began this project assuming young mothers would be struggling and that the birth of a preterm infant would add additional stress. The notion that being a mother might positively affect a young woman was something I had not considered and was reflected in my early assumptions and use of a deficit model to frame the larger project. The shift in my thinking early in the research process allowed me to challenge my own assumptions, and to view the data and experiences of these young mothers in terms of positive change as well as challenges. Consistent with a hermeneutic circle, I have come back to the consideration of challenges for young mothers, while being consciously aware of being open to the nuances and complexities.

\section{Findings}

Despite the researchers' focus on preterm birth, birth status did not meaningfully differentiate the young women's narratives, but did inform the main themes. The first theme that emerged was 'The actual/ideal incongruence”, which describes how the experience of being a mother as an adolescent is one of reconciling the incongruence between actual experiences and idealised notions related to parenting. The second theme "transforming self" discusses how motherhood shapes the way young women think about themselves. Table 2 provides an overview of the two themes and subthemes.

Table 2

Themes and subthemes

\begin{tabular}{ll}
\hline Theme & Subthemes \\
\hline The actual/ideal & The idealised view of self as a \\
incongruence & mother
\end{tabular}

The idealised father

Transforming self Changing trajectory: going the Decreased risk taking behaviour other way 
Motherhood as a vehicle for change

Creating meaning and purpose

Growth and development

Who I was and who I became

\section{The actual/ideal incongruence}

The theme actual/ideal incongruence captures the incongruity between how the mothers expected the experience of being a mother would be and how it was. Although there were different facets to this incongruence, it was evident in all but two mother's narratives (Clare and Juliana), particularly at time 1 and 2.

Idealised view of self as a mother. Virtually all mothers noted that prior to becoming/being a mother they had experience caring for siblings or as babysitters. This previous experience was offered as justification for their suitability to be mothers. Early in the parenting experience, and particularly for mothers of preterm infants who had not yet taken their babies home, this experience was deemed to be enough, and the young women lamented the lack of acknowledgement for their perceived pre-existing skills by nurses at the hospital. However, over their course of the first year of parenting many of the young women openly acknowledged that these skills were not enough to prepare them for parenting.

I think because you're responsible for your actions with your baby. Whereas if you're actually babysitting them...It's completely different. You go home at the end of the day. Whereas you're stuck with your baby 24/7. I had a complete turnaround once I had my own kid. I was like, “Wow, this is nothing like that.” (Bronte T3 PT). Mothers of preterm infants espoused idealised notions of motherhood and what it would mean to be a mother when their infant came home.

It will be so much better when he’s home ... I'll be able to just sit down and sleep when he is asleep and just relax. (Renee T1 PT).

However, in reality mothering was much harder once the infant came home. 
Motherhood as a vehicle for change

I couldn’t wait to get him home and when I got him home it was like, “Can we go back to the nursery?” Because at least I could sleep. I was so tired. (Renee T2 PT). Uncertainty about caring for their infants was attributed to the hospital environment rather than to the ambiguity associated with mothering.

So once she's home she'll be able to cry when she wants something to eat. She'll be able to cry when she’s got a dirty nappy. So I'll be able to go, alright I know that cry.... But at the moment it’s, “Okay, what's she crying about now? She’s just been fed, I've just cleaned her bottom, what is it? (Laura T1 PT).

As such, the young women presumed that when the environment changed, so too would their confidence in parenting, whereas in reality this was not the case. Transitioning home from the hospital was then experienced as a "reality check" (Jade T2 PT).

The young women held themselves to an idealised internal standard, with a strong link between how well they managed the care of the infant and how they felt about themselves as mothers. Of note, the benchmark for this internalised/idealised standard was primarily to avoid being a 'stereotypical' teenage mother. Therefore, the standards were of what not to do, rather than what to do.

I’ve got a cousin who has a baby and her child goes to her mother every second day and she goes out clubbing and drinking... I don't like leaving her with my mum...I feel that then my mum’s like “well, you're just a party animal”...sometimes I’m just at the point where I'm like I just want to drop you to your grandmother's but I don't, I can’t (Jenna T2 PT).

The young women presented images of themselves as someone who was coping and managing. At times, this ideal was held rigidly, resulting in the young women not asking for help. For some, not asking for help was about impression management. "It sort of makes me uncomfortable, being around other people and their babies because like I'm on show. I'm 
Motherhood as a vehicle for change

trying to impress them sort of thing. See who can be a better mum than the other" (Renee T3 PT). These words expressed a fear or discomfort at being compared to other mothers and, taken together, the excerpts above suggested young women worried about their parenting actions and needs exposing them as "not good enough" parents and feared this would be recognised and pointed out by others. Feelings of being judged were also present when the young mothers sought help from medical professionals. "I felt like I was being judged as a mother and not knowing why he was crying, and then I felt that I wasn’t succeeding at being a mum, at one point, because of that” (Bronte T3 PT).

The idealized father. The idealization of the father, discussed by some of the mothers, was striking. For several mothers, a misfit or incongruence between the idealization and the reality of experience was evident in their expectations of how a father should/would behave (time 1) and their experience with the fathers of their infants over time (time 2/3). This was particularly notable for the young mothers who were in new or unstable relationships with the father of their infant. Their desires and expectations of how the father would be were at the forefront, and his capacity/desire to change his prior behaviour was overlooked.

I want to stay over here [in Queensland] because Bailey’s dad's over here... I want Bailey to have his father ... I know his father, he'll do the right thing ...he’s nearly 32 and he needs to settle down as well. Like he’s a real party person ....and I think having Bailey will settle him down. (Tenielle T1 FT).

I let [father] have [baby Bailey] and he drove past me without Bailey in the car, and I saw red as soon as he drove past without my son in the car...Just the fact that he could leave him... (Tenielle T2 FT).

Emily, who was not in a relationship with the father of her baby, also idealised the role of a father for her baby, ignoring the biological father's history of abuse. 
Motherhood as a vehicle for change

I just wanted to know if he was like going to participate in paying child support and stuff like that ... 'cause he’s got a child already... he threatened to tie bricks to its feet and throw it in the dam. (Emily T1 PT).

Emily continued to be attached to the idea that Nathan should do more, despite describing his lack of interest or suitability to be a father.

People say to me "You can’t do it on your own” and like I tried to tell Nathan that I needed help and like "You're her father so you're supposed to step in and be the father”.” (Emily T2 PT).

While there was no evidence of child abuse or harm to any of the infants, and most fathers were not engaging in high risk behaviours, these quotes suggest the desire to have the father involved may have blinded the mother to the potential for harm. The struggle of 'doing it on my own' came through, suggesting that for many mothers, any father was better than no father. This was also evident in the discourse of the young women who were in stable relationships, who had idealized notions about the father of the baby's involvement in caretaking duties.

I know that he's going to let me sleep in in the mornings her feeds at 6.30 so I reckon he’s going to sit there feeding her ... before he goes to work ...I reckon he’s going tell his boss, I won’t be at work until 7 o’clock because he starts at 6.30. (Holly T1 PT). Holly was expecting the father of the baby to prioritise her need to sleep over his work, also expecting that the father would negotiate a new start time with his boss. Instead, she was confronted with a father who did not meet these expectations.

The young women described a deep seated belief that these men would do 'the right thing' and become 'fathers' by contributing emotionally and financially to the care of the infant, while also prioritising both mothers' and infants’ needs in their lives. They disregarded contradictory evidence to preserve the belief in the idealized father. 


\section{Transforming Self}

Figure 1: Motherhood as transforming the self

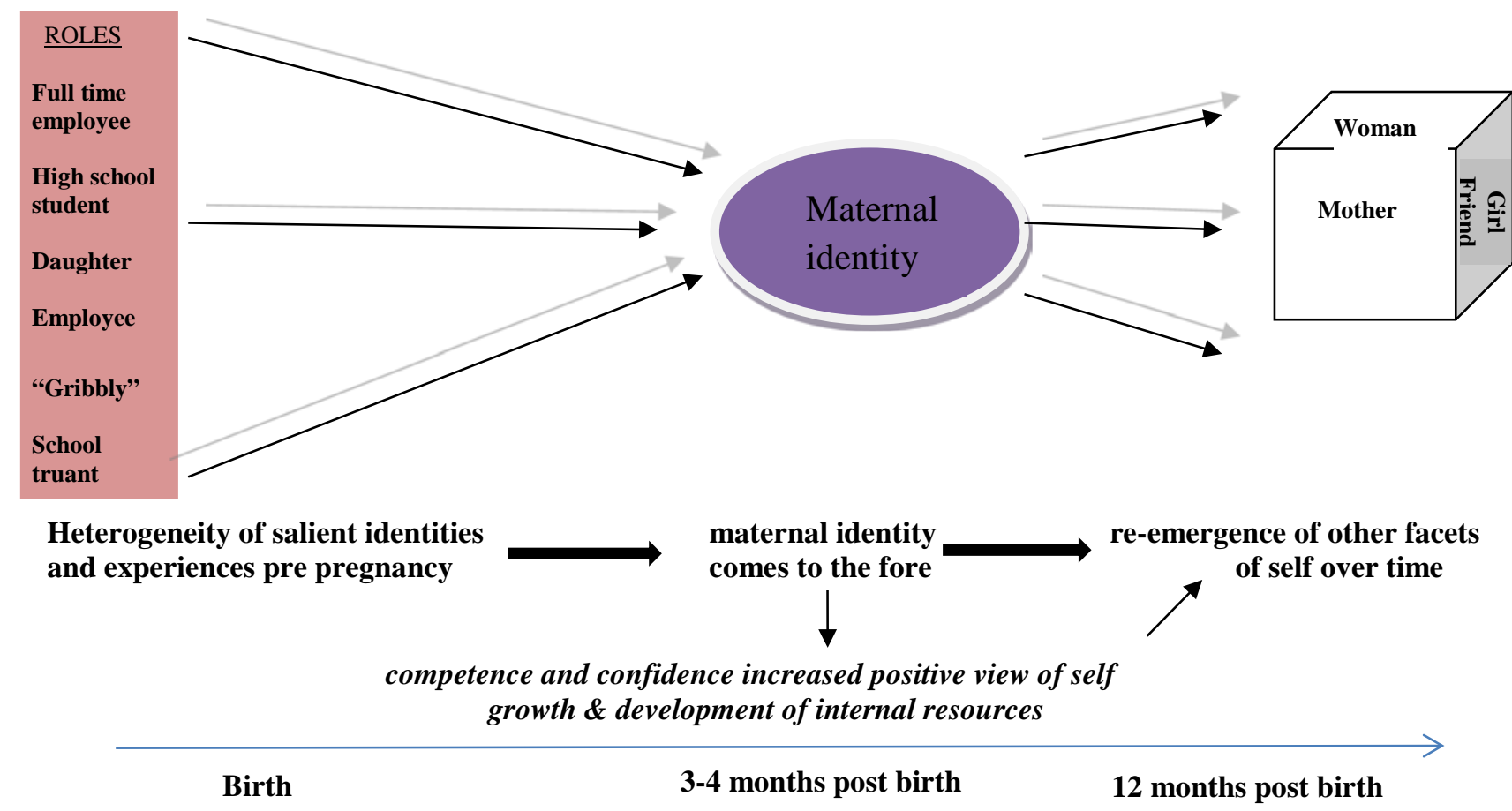

Figure 1: relational presentation of core processes and themes occurring over time. Rectangle on left represents roles pre-pregnancy with arrows representing the convergence towards maternal identity for all mothers' post- birth. Becoming a parent led to a transformation of identity and change in perceptions of self, followed by reflection about whom they were and who they then became. The final three dimensional square on the right represents how the young women felt their identities were becoming more multifaceted, with maternal identity one of several emerging adult identities (personal, relational \& social).

The theme 'transforming self' explores how the young women discussed the process of becoming mothers as young women. This process is graphically represented in Figure 1. At the time of pregnancy the young women were a heterogeneous group; for some of the young women there was a sudden and dramatic disjuncture between who they were as young women and who they became as mothers, while for others motherhood involved more subtle changes. These changes are described in the subtheme 'changing trajectory: going the other way'. After birth, there was an immersion in the maternal identity for all young women, often to the exclusion of other identities/roles. There was a progression in how the young women 
Motherhood as a vehicle for change

defined themselves, from who they were as young women, to who they became as mothers. This is discussed in subthemes 'Creating meaning and purpose' and 'Growth and development'. Over time, the women came to a deeper, more meaningful understanding of who they were as both young women and mothers. This process is discussed in the theme 'Who I was and who I became'.

Changing trajectory: going the other way. Many of the young women described a self-perception of who they were pre-pregnancy that was in stark contrast to who they became following the birth of their infants. The young women described the process as having "gone the other way" (Emily T1 PT), indicating how pregnancy and becoming a mother altered the trajectory for the young woman. 'Going the other way' was associated with three main areas of change: Decreased risk taking behaviour and increased prosocial behaviour (i.e., acting responsibly, including not going out or engaging in silly acts), growth and development, and creating meaning or purpose in the young women's lives; that is, pregnancy prevented the young women from continuing on a life trajectory that they reflected on as “wrong” (Emily T3 PT).

Things happen for a reason and I think having her happened for a reason. God had a reason for her. Because I think I was heading right down the wrong track. If I didn't have her I think I would be in a very sad situation. (Emily T3 PT).

This perception was particularly interesting, as it differs from society's perception of teen pregnancy being the 'wrong track'.

Decreased risk taking behaviour. Becoming a mother was associated with a sometimes drastic shift in trajectory away from drug and alcohol use, and other risky behaviours, towards behavioural choices perceived as safe or 'proper' behaviours particularly for Laura, Emily, Holly, and Teneille. 
Motherhood as a vehicle for change

Okay, you know how you at night time you see all the... 14, 15, 16 year olds running around drunk; that's a gribbly. So, yeah, I was one of those. I used to run around drunk all the time. (Laura T3 PT).

The change in trajectory from pre to post pregnancy was still echoed in their stories 12 months later, suggesting changes away from high risk behaviours made during pregnancy were maintained over time, as they mothered.

I’ve been a lot more quieter. I don’t drink as much. I used to drink heaps before I fell pregnant, now I'll be lucky to even go to the pub, or go to the shop to even buy any drinks and anything and...I just don't want to... It's just not worth the effort. (Tenielle T3 FT).

Creating meaning and purpose. Not all of the young women had been engaging in high risk teenage behaviours. Instead, the actions and meaning making of motherhood for these mothers resulted in a transformation of the self around the profoundly fulfilling nature of motherhood and having a family. Instead of turning away from a newly defined 'wrong path', these women moved towards the life path of creating a family. For young women such as Danielle, Claire, Bronte, and Skye, becoming a mother fulfilled an existential need at the core of their existence, and their discourse centred on how having an infant fulfilled their plans.

We did plan it because I'm not the type of person who likes to go out and party. I'm more of a family oriented person... we'll have another one just after we get married...We plan to have 4 kids so. Yeah, so we're happy with that. (Claire T1 FT). They talked of how having a baby gave them meaning, a role they could fulfil, and a sense of purpose in their lives. 
Motherhood as a vehicle for change

That's the reason why I wanted him cause I had nothing else, I had no career, nothing you know... Cause there was nothing there and now my day's not going to be empty, I’m not going to be lonely and I'm not going to be bored. (Skye T1 PT).

Being a mother was seen by the young women as doing something right in the world and increasing their importance. "I am important now I have to do it... they're not going to be looking after him for the rest of his life, I'm going to be looking after him” (Jade T1 PT). Further, becoming a mother provided the young women's self-concept with positive attributes, often filling what was previously a predominantly negative view of self. "You know I look at him and it feels like I finally did something right., it’s good” (Renee T2 PT). The infant was also perceived as an extension of the self - a part of themselves out in the world. 'It's just a really really good feeling being able to hold her something that you've made. Its good” (Juliana T1 PT).

Growth and development. Becoming mothers provided all the young women with opportunities to grow and develop. They described themselves as becoming more mature, less self-focussed (egocentric), and more other-focussed as a result of becoming mothers.

Just making me wake up and grow up and see the world in a different way. ...it's not all about me it’s all about her now. It's different...I was young and just wanted my life... and then she turned up and everything changed. But that's why I'm saying it's good. It's made me stop and think and grow up a bit. (Lily T3 PT). The development of internal resources, such as developing confidence and competence, becoming more organized and patient, and developing more resilience to negative judgments and increased assertiveness, was a process over time. That is, for most young women, selfgrowth, development, and change continued throughout the process of doing mothering. Further, the young women described how over the course of the year they had become 
Motherhood as a vehicle for change

"strong minded” (Jade T3 PT). This enabled them to stand up to criticism or unwanted advice from others.

This increased confidence and competence in parenting also meant most of the young women perceived a reduced need for support over time. Aiding the young women in their development of parental efficacy was the realization that others, including professionals, were not always right.

[doctor said] you know, there’s nothing wrong with him.” And I kept looking at his doctors and go, “I know he does [have whooping cough].” I could hear him cough. And then they got a doctor to fly in from Sydney who walked straight in and went, “Oh, he’s got whooping cough,” and I went, “Wow, congratulations.” (Renee T3 PT). The more the young women's instincts were correct, the more confident they became in their parenting ability. The young women described learning through accessing advice from multiple others, using trial and error, and eventually moving to an integration of their best guess and trial and error. The ambiguity surrounding parenting and what may or may not be best for their infants, while initially causing distress and uncertainty, eventually became the catalyst for trusting their own instincts and developing their confidence.

Two young women's narratives reflected a contrary experience from most of the other mothers: Claire and Julianne. Both appeared confident and competent in their parenting ability from the outset, with neither expressing uncertainty or a lack of confidence in their role. Both presented as assertive in their parenting roles, able to stand up to grandparents in order to assert their own rules for their infants.

Of potential importance, Claire had completed high school, attended a semester of university, and had worked in a semi-professional role in a financial company prior to becoming pregnant. Similarly, Juliana, despite leaving school in grade ten, had completed a TAFE course and was working as a beautician prior to her pregnancy. Both women were in 
Motherhood as a vehicle for change

stable relationships with men who owned their own homes and had secure employment. These factors suggest both women had had opportunities to develop a range of internal resources prior to their pregnancies, which may have added to their sense of confidence in parenting. In contrast, for most of the other young women the development of these internal resources occurred over time via the process of being a mother.

Who I was and who I am now. Early in the experience of being mothers, the young women's narratives focussed on the transformative trajectories away from risk taking behaviours or towards fulfilment from motherhood and family. Over time, the young women shifted from thinking about themselves primarily as mothers to thinking about themselves as young women and mothers. Initially, the predominance of the developing maternal identity meant mothers suspended the development of their individual and other social identities, perceiving this would happen in the future. Perceptions were that life is long and parenting shorter, there would be time later for them to become who they wanted to be through education, work, etc. “Got the rest of my life ahead of me so it doesn’t really matter for the time being...can’t do as much but I'm pretty fine with it.” (Juliana T1 PT).

Over the 12 months there was, however, a return to considering who they were as young women beyond their roles as mothers.

I think finding myself as a person again was another issue too, because you change...I have started to find myself again. We're on a long road here [laughs]... Then I think it's just the change in general, such a massive thing. You think you've lost yourself but you really haven’t. I feel more like the old Bronte. (Bronte T3 PT).

Bronte continued, explaining how she perceived changes in her sense of self - her identityduring the process of being a mother.

You're a teenager and to put on that role as a mother, you do change. Now I've got both sides. At one point I didn't have me. I had the mother in me, but now I'm getting 
Motherhood as a vehicle for change

the old Bronte back and I'm a mum as well. So it's just really learning to take on that role and being comfortable with it, I think...I think you have to be a mum but you also have to show them that you have, you're your own person. (Bronte T3 PT).

\section{Discussion}

In the IPA qualitative research tradition, we conclude with a final phase of interpretation, where the research findings are integrated with previous empirical findings and theory (Smith et al. 2009). Initially we discuss the findings in light of narrative identity development, followed by the impact of preterm birth on identity development and the role of idealization.

\section{Developing a narrative identity}

Consistent with the perspective that people construct stories to make sense of their lives (McAdams, 1993), our findings suggest motherhood created a way for the young women to formulate a meaningful life story. Motherhood shaped their narratives into coherent stories of either "I was bad but now I have done something good” or "I was good and motherhood was an obvious path for me”. Either way, all of the young mothers concluded "motherhood is the right path for me" and this validated their decision to be a mother at an early age. The infant and being a mother were integrated into the young women's narratives as fulfilment of a purpose in life and of placing their lives either on the right or a different track with less risks; adding to a growing body of qualitative research suggesting that teenage mothers experience motherhood as a positive life-changing event (Barratt et al., 1996; Breen, 2014; Breen \& McLean, 2010; Hanna, 2001; Spear \& Lock, 2003). The women's narratives around motherhood set them apart from same aged peers who either had children but were not 'good' mothers or who did not have children but were involved in risky or deviant behaviours. 
Motherhood as a vehicle for change

The sense of agency from motherhood(McAdams \& McLean, 2013) was also evident in the narratives of mothers who planned to become mothers in adolescence, where motherhood fulfilled a life goal and existential need. These mothers were more likely to be in stable relationships with the father of the baby. For these women, motherhood was a source of eudemonic well-being (Bauer, McAdams, \& Pals, 2008), where motherhood was appraised as good and explicitly linked to their sense of meaning and virtue in life. Personal growth was emphasized in these women's life stories, as was the transformative nature of the difficult life experiences associated with parenting, where the women suffered but gained new insights into themselves (Bauer et al.).

There was also evidence in some mothers' narratives of a redemption narrative (McAdams \& McLean, 2013); where this potentially negative event (being a teen mother usually unplanned and/or after casual sex) was good, changing their lives in positive ways. Mothers expressing this view were also most likely to describe motherhood as the trigger event for decreased risk taking behaviour and increased prosocial behaviour. Breen (2014) found having a child was a positive development in the lives of young women engaged in antisocial behaviour. Breen posited that having a child allowed the women to see themselves in a new light, as the value attached to the child was seen as an extension of the self, contributing to an increased valuing of one's self. Our findings are consistent with this proposition, with several mothers describing how motherhood and successfully caring for their infant improved their self-concept. They narrated the ways they had had to change to accommodate the infant. Being a mother made the mothers feel important and as though they had done something right, suggesting how they defined themselves as mothers was based on the infant and how well they engaged in mothering.

Over time, the young women's narratives suggested that, as they accommodated motherhood and parenting, their focus returned to the development of other relational and 
Motherhood as a vehicle for change

social identities, transformed in various ways by being mothers. There was also evidence of the mothers integrating and maintaining positive changes that occurred during the early mothering experience. This process is similar to what has been found with adult mothers, when after birth and adjustment to the presence of the child, attention returns to life projects which have been transformed by the process of being a mother (Smith, 1999).

\section{Identity and preterm birth}

Several features of the young women's narrative were notable by their absence. One absence was that mothers of preterm infants did not report that preterm birth disrupted the meaning having a baby gave to their life. Being a young mother of a preterm infant and initially parenting their infant in a hospitalized environment did not significantly distinguish their narratives from those who did not have these experiences. The young women saw and described themselves as 'mother', suggesting the experience was not one of being 'preterm'

or of being 'teenage'. This contrasts with older mothers, where the development of maternal identity was delayed for many older mothers of preterm infants (Mercer, 1995) and narratives were shaped by denied maternal role experiences (Zabielske, 1994).

\section{The role of idealization}

Idealization served a self-protective role for some young women, helping them defend against fears of not being good enough or not being able to cope. Much has been made of the negative role of idealization in adolescent parenting (Condon, Donovan, \& Corkindale, 2001), however our research highlights the self-protective nature of idealization as it helped them cope with the situation.

The findings also showed how early in the experience of being a mother, the young women desired and looked forward to their infant being a shared experience between mother and father. The role the father of the baby would play was idealised and he may have had little chance of meeting the mother’s expectations. Further, the young women ignored 
contrary information from past experience, perhaps expecting the birth of the infant to have as dramatic transformative effect on the father as it had for them as mothers.

There was also a relationship between identity development and idealization processes. Early in the parenting experience women were more likely to idealize themselves and others in order to defend against fears of not being 'good enough' mothers. However, with parenting experience these young women relied more on themselves and less on idealization.

Much has been made of the role of support for successful parenting as a young woman (Clemmens, 2001; Letourneau, Stewart, \& Barnfather, 2004). However, our findings suggest when a young woman perceives a discrepancy between her own ideal of a parent and her actual experience of herself as a parent, she is unlikely to access help or admit she needs help. Further, the women minimised contact with people who challenged their view of self as a competent mother. The young women were aware of the both the stereotype of teenage mothers and the stereotype of a 'good' mother (Arendell, 1999) and this affected their help seeking behaviour. This suggests service providers should consider the young woman's willingness to access support and not just whether there is support available. Service providers also need to be more aware of not excessively challenging the young mother's sense of competency.

\section{Implications}

The young women in our study categorized themselves as women and mothers first and as teenage second. People working with young women or their infants need to be aware of the labels they use and how they categorize young women. Labeling young mothers as a mother first and acting in accordance with this may reduce their perceptions of being judged negatively based on age. Similarly, people working in services supporting young mothers need to ensure their practices are similar for all mothers regardless of age and to be aware of 
Motherhood as a vehicle for change

their preconceptions. Further, people working in this area need to be aware of, and address, young women's appraisals of differential treatment as being age based.

People working with young women should also be aware that some young women hold idealized images of themselves as mothers. In defending against fears that they may not be good enough parents or may be stereotypical teenage mothers, young women may minimize contact with people who are perceived to reinforce this belief and thus a strengths based approach would be beneficial. Providing reassurance and building a trusting relationship may be integral in engaging young women. The current research further suggests that young women become more open to intervention as they develop confidence and competence in the parenting role. In many ways working successfully with young women is about dialectics. That is, reassuring the young women that who they are and what they are doing is good, while moving the young women towards change and improving skills.

Honouring the young women's need for autonomy and appreciating that the process of being a mother is often the mechanism for self-development may help those in support roles to target their support more effectively. Given the heterogeneity of the group and the differing support needs, staff should avoid a standardized care approach, instead targeting interventions to those who have not previously had opportunities to develop confidence and competence in parenting.

\section{Limitations and future directions}

Our study was limited to mothers above the age of 15 . There is growing acknowledgement that becoming a mother as a 12 to 14 year old may engender far greater challenges than those experienced by older adolescents (Malabarey, Balayla, Klam, Shrim, \& Abenhaim, 2012; Smid, Martins, Whitaker, \& Gilliam, 2014). Future research is warranted to explore the impact of motherhood on the self, as well as the processes utilised by younger adolescents as they negotiate motherhood. 
Motherhood as a vehicle for change

Australia has relatively low rates of teenage pregnancy, good financial support available via government welfare payments, and relatively low rates of unemployment, suggesting the relative SES of Australian mothers generally is higher than other countries (i.e., US). As such, contextual factors may limit generalisability to other countries. In addition, the majority of the mothers in the current study were White. Further research is warranted to explore how the experience of motherhood varies across ethnicities, cultures, and countries.

\section{Conclusion}

Our research suggests that the experience of being a mother, regardless of infant birth status, was primarily about change to self. The young women constructed themselves differently as a result of being mothers and parenting became the vehicle for positive selfgrowth over time. However, they also idealised motherhood and fought against the social construction of teenage motherhood. Our research demonstrates the similarities in the experience of being a mother for young mothers of preterm and full-term infants and helps reduce the assumptions made about the needs of these women. 


\section{References}

Arendell, T. (1999). Hegemonic motherhood: Deviancy discourses and employed mothers' accounts of out-of-school time issues (Center for Working Families Working Paper No. 9). Berkeley: Unversity of California.

Arendell, T. (2000). Conceiving and investigating motherhood: The decade's scholarship. Journal of Marriage and Family, 62, 1192-1207.

Barratt, M. S., Roach, M. A., Morgan, K. M., \& Colbert, K. K. (1996). Adjustment to motherhood by single adolescents. Family Relations, 45, 209-215.

Bauer, J. J., McAdams, D. P., \& Pals, J. L. (2008). Narrative identity and eudaimonic wellbeing. Journal of Happiness Studies, 9, 81-104. doi: DOI 10.1007/s10902-006-9021-6

Bearinger, L. H., Sieving, R. E., Ferguson, J., \& Sharma, V. (2007). Global perspectives on the sexual and reproductive health of adolescents: patterns, prevention, and potential. Lancet, 369, 1220-1231. doi: 10.1016/S0140-6736(07)60367-5

Bradbury, B. (2006). Disadvantage among Australian young mothers. Australian Journal of Labour Economics, 9(2), 147-171.

Breen, A. V. (2014). Changing behaviour and changing personal identity: The case of pregnant and parenting young women and antisocial behaviour. Identity: An International Journal of Theory and Research, 14(1), 60-79. doi: 10.1080/15283488.2013.858225

Breen, A. V., \& McLean, K. C. (2010). Constructing resilience: Adolescent motherhood and the process of self-transformation. In K. C. McLean \& M. Pasupathi (Eds.), Narrative Development in Adolescent. New York: Springer.

Campion, M. J. (1995). Who's Fit to be a Parent? London: Rouledge.

Carter, J. D., Mulder, R. T., Bartram, A. F., \& Darlow, B. A. (2005). Infants in a neonatal intensive care unit: parental response. Archives of Disease in Childhood - Fetal and neonatal edition, 90, F109-F113. doi: 10.1136/adc.2003.031641

Clemmens, D. (2001). The relationship between social support and adolescent mothers' interactions with their infants: A meta-analysis. Journal of Obstetric, Gynecologic and Neonatal Nursing, 30(4), 410-420. doi: 10.1111/j.1552-6909.2001.tb01560.x

Condon, J. T., \& Corkindale, C. J. (2002). Teenage pregnancy: Trends and consequences. Current Therapeutics, 43(3), 25-31.

Condon, J. T., Donovan, J., \& Corkindale, C. J. (2001). Australian adolescents' attitudes and beliefs concerning pregnancy, childbirth and parenthood: the development, psychometric testing and results of a new scale. Journal of Adolescence, 24(6), 729742. doi: 10.1006/jado.2001.0439

Cowan, C. P., \& Cowan, P. A. (2000). When partners become parents: The big life change for couples. Mah Way, NJ: Lawerence Erlbaum Associates.

Davis, L., Edwards, H., \& Mohay, H. (2003). Mother-infant interaction in premature infants at three months after nursery discharge. International Journal Of Nursing Practice, 9(6), 374-381. doi: doi:10.1046/j.1440-172X.2003.00447.x

Erikson, E. (1968). Childhood in Society. New York: W.W.Norton.

Farnell, L., Jones, L., Rowe, J., \& Sheeran, N. (2012). Effects of age and the preterm birth of an infant on adolescent mothers' psychological adjustment. Child Health Care, 41(4), 302-321. doi: 10.1080/02739615.2012.721713

Fletcher, J. M. (2012). The effects of teenage childbearing on the short- and long-term health behaviors of mothers. Journal of Population Economics, 25(1), 201-218. doi: 10.1007/s00148-011-0381-9

Gilligan, C., \& Belenky, M. F. (1980). A naturalistic study of abortion decisions. New Directions for Child Development, 7, 69-90. doi: 10.1002/cd.23219800706 
Hanna, B. (2001). Negotiating motherhood: the struggles of teenage mothers. Journal of Advanced Nursing, 34(4), 456-464. doi: 10.1046/j.1365-2648.2001.01774.x

Hunt-Morse, M. C. (2002). Adolescent mothers' psychosocial development: Implications for parenting. (Doctor of Philosophy), University of Oregon, Oregon.

Kleiber, B. V., \& Dimidjian, S. (2014). Postpartum depression among adolescent mothers: A comprehensive review of prevalence, course, correlates, consequences, and interventions. Clinical Psychology: Science and Practice, 21(1), 48-66. doi: 10.1111/cpsp.12055

Kumar, R., Kumar Singh, P., Kumar, C., \& Parasuraman, S. (2013). Teenage childbearing: a growing public health concern in need of unrgent policy and program action. Journal of Public Health, 21, 379-384. doi: DOI 10.1007/s10389-012-0551-6

Lee, C., \& Gramatnev, H. (2006). Predictors and outcomes of early motherhood in the Australian longitudinal study on women's health. Psychology, Health, \& Medicine, 11(1), 29-47.

Letourneau, N. L., Stewart, M., J., \& Barnfather, A. K. (2004). Adolescent mothers: Support needs, resources, and support-education interventions. Journal of Adolescent Health, 35, 509-525. doi: 10.1016/j.jadohealth.2004.01.007

Li, Z., Zeki, R., Hilder, L., \& Sullivan, E. A. (2013). Australia's mothers and babies 2011. Perinatal statistics series no.28. Cat no. PER 59. Canberra: AIHW National Perinatal Epidemiology and Statistics Unit.

Malabarey, O. T., Balayla, J., Klam, S. L., Shrim, A., \& Abenhaim, H. A. (2012). Pregnancies in young adolescent mothers: A population-based study on 37 million births. Journal of Pediatric and Adolescent Gynecology, 25(2), 98-102. doi: 10.1016/j.jpag.2011.09.004

McAdams, D. P. (1993). The stories we live by: Personal myths and the making of the self. New York The Guilford Press.

McAdams, D. P., \& McLean, K. C. (2013). Narrative identity. Current Directions in Psychological Science, 22(3), 233-238. doi: 10.1177/0963721413475622

McLean, K. C., \& Pasupathi, M. (2012). Processes of identity development: Where I am and how I got there. Identity: An International Journal of Theory and Research, 12(1), 828. doi: 10.1080/15283488.2011.632363

Meeus, W. (2011). The study of adolescent identity formation 2000-2010: A review of longitunidal research. Journal of research on adolescence, 21(1), 75-94. doi: 10.1111/j.1532-7795.2010.00716.x

Mercer, R. T. (1980). Teenage motherhood: The first year. Journal of Obstetric, Gynecologic, \& Neonatal Nursing, 9(1), 16-26. doi: 10.1111/j.15526909.1980.tb01301.x

Mercer, R. T. (1995). Becoming a mother. New York: Springer Publishing Company Ltd.

Mercer, R. T. (2004). Becoming a mother versus maternal role attainment. Journal of Nursing Scholarship, Third quarter, 226-232. doi: 10.1111/j.1547-5069.2004.04042.x

Meyer, E. C., Garcia Coll, C. T., Seifer, R., Ramos, A., Kilis, E., \& Oh, W. (1995). Psychological distress in mothers of preterm infants. Journal of Developmental and Behavioral Pediatrics, 16(6), 412-417. doi: 10.1097/00004703-199512000-00004

Miles, M. S., Holditch-Davis, D., Schwartz, T. A., \& Scher, M. (2007). Depressive symptoms in mothers of prematurely born infants. Journal of Developmental and Behavioural Pediatrics, 28, 36-44. doi: 10.1097/01.DBP.0000257517.52459.7a

Piaget, J. (2001). The stages of the intellectual development of the child. In M. Guauvain \& M. Cole (Eds.), Readings on the development of children (pp. 17-21). New York: Worth Publishers. 
Reid, T. (2000). Maternal identity in preterm birth. Journal of child health care : for professionals working with children in the hospital and community, 4(1), 23-29.

Riva Crugnola, C., Ierardi, E., Gazzotti, S., \& Albizzati, A. (2014). Motherhood in adolescent mothers: Maternal attachment, mother-infant styles of interaction and emotion regulation at three months. Infant Behavior and Development, 37(1), 44-56. doi: 10.1016/j.infbeh.2013.12.011

Romagnoli, A., \& Wall, G. (2012). 'I know I'm a good mom’: Young, low-income mothers' experiences with risk perception, intensive parenting ideology and parenting education programmes. Health, Risk \& Society, 14(3), 273-289. doi: 10.1080/13698575.2012.662634

Sadler, L. S. (1983). The adolescent parent: A dual developmental crisis. Journal of Adolescent Health Care, 4, 100-105.

Shaw, R. J., Bernard, R. S., Storfer-Isser, A., Rhine, W., \& Horwitz, S. M. (2013). Parental coping in the neonatal intensive care unit. Journal of Clinincal Psychololgy in Medical Settings, 20(2), 135-142. doi: 10.1007/s10880-012-9328-x

Sheeran, N. (2012). Young women's experiences of being a mother to preterm infants: An interpretative phenomenological analysis (IPA) approach. (Doctor of Philosophy), Griffith University, Brisbane, Australia.

Sheeran, N., Jones, L., \& Rowe, J. (2013). The relationship between maternal age, communication and supportive relationships in the neonatal nursery for mothers of preterm infants. Journal of Neonatal Nursing, 19(6), 327-336. doi: 10.1016/j.jnn.2013.01.006

Sheeran, N., Jones, L., \& Rowe, J. (in press). Joys and challenges of motherhood for Australian young women of preterm and fullterm infants: An Interpretative Phenomenological Analysis. Journal of Reproductive and Infant Psychology. doi: 10.1080/02646838.2015.1042962

Smid, M., Martins, S., Whitaker, A. K., \& Gilliam, M. (2014). Correlates of pregnancy before age 15 compared with pregnancy between the ages of 15 and 19 in the United States. Obstetrics \& Gynecology, 123(3), 578-583. doi: 10.1097/aog.0000000000000136

Smith, J. A. (1999). Identity development during the transition to motherhood: An interpretative phenomenological analysis. Journal of Reproductive and Infant Psychology, 17(3), 281-299. doi: 0264-6838/99/030281-19

Smith, J. A. (2011). Evaluating the contribution of interpretative phenomenological analysis. Health Psychology Review, 5(1), 9-27. doi: 10.1080/17437199.210.510659

Smith, J. A., Flowers, P., \& Larkin, M. (2009). Interpretative phenomenological analysis: Theory, method and research London: Sage.

Smith, J. A., \& Osborn, M. (2008). Interpretative phenomenological analysis. In J. A. Smith (Ed.), Qualitative Psychology: A practical guide to research methods (2nd ed., pp. 53-80). London, England: Sage.

Smith, J. A., Osborn, M., \& Jarman, M. (1999). Doing interpretive phenomenological analysis. In M. Murray \& K. Chamberlain (Eds.), Qualitative health psychology: theories and methods. London: SAGE.

SmithBattle, L. (2012). Moving policies upstream to mitigate the social determinants of early childbearing. Public Health Nursing, 29(5), 444-454. doi: 10.1111/j.15251446.2012.01017.x

SmithBattle, L. (2013). Reducing the STIGMATIZATION of Teen Mothers. MCN, the American Journal of Maternal Child Nursing, 38(4), 235. 
Spear, H. J., \& Lock, S. (2003). Qualitative research on adolescent pregnancy: a descriptive review and analysis. Journal of Pediatric Nursing, 18(6), 397-408. doi: 10.1016/S0882-5963(03)00160-X

The National Health and Medical Research Council, The Australian Research Council, \& The Vice-Chancellors' Committee. (2007). National Statement on Ethical Conduct in Human Research. (E72). Canberra: National Health and Medical Research Council.

Whitfield, M. F. (2003). Psychosocial effects of intensive care on infants and families after discharge. Seminars in Neonatology, 8, 183-193. doi: 10.1016/S1084-2756(02)00218$\mathrm{X}$

Williams, H., \& Davidson, S. (2004). Improving adolescent sexual and reproductive health. A view from Australia: learning from world's best practice. Sexual Health, 1(2), 95105. doi: http://dx.doi.org/10.1071/SH03023

Yardley, E. (2008). Teenage mothers' experiences of stigma. Journal of Youth Studies, 11(6), 671-684. doi: 10.1080/13676260802392940

Zabielske, M. T. (1994). Recognition of maternal identity in preterm and fullterm mothers. Maternal-Child Nursing Journal, 22(1), 2-36.

Zimmer-Gembeck, M. J., Ducat, W., \& Collins, W. A. (2011). Autonomy development during adolescence. In B. B. Brown \& M. Prinstein (Eds.), Encyclopedia of Adolescence. Oxford: Elsevier. 